This is the peer-reviewed version of the following article:

William J. Kerr, Jason D. Williams, Stuart Leach and David M. Lindsay, "A Practical and General Amidation Method from Isocyanates Enabled by Flow Technology", Angew. Chem. Int. Ed. 2018, doi: 10.1002/anie.201807393

which has been published in final form at https://doi.org/10.1002/anie.201807393. This article may be used for non-commercial purposes in accordance with Wiley- $\mathrm{VCH}$ Terms and Conditions for Self-Archiving. 


\title{
A Practical and General Amidation Method from Isocyanates Enabled by Flow Technology
}

\author{
Jason D. Williams, ${ }^{[a, b]}$ William J. Kerr, ${ }^{*[a]}$ Stuart G. Leach, ${ }^{*[b]}$ and David M. Lindsay ${ }^{[a]}$
}

Abstract: The addition of carbon nucleophiles to isocyanates represents a conceptually flexible and efficient approach to the preparation of amides. This general synthetic strategy has, however, been relatively underutilized, due to narrow substrate tolerance, and the requirement for less favourable reaction conditions. Herein, we disclose a high-yielding, mass efficient, and scalable method with appreciable functional group tolerance for the formation of amides by reaction of Grignard reagents with isocyanates. Through the application of flow chemistry, and the use of sub-stoichiometric amounts of $\mathrm{CuBr}_{2}$, this process has been developed to encompass a broad range of substrates, including reactants found to be incompatible with previously published protocols.

The carboxamide is a ubiquitous motif within molecules which find use in the pharmaceutical, agrochemical, and other chemical industries. ${ }^{[1]}$ Accordingly, over recent years, efforts have focused on improved methods for amide formation which avoid the use of stoichiometric activating agents. Whilst the majority of this focus has been on catalysts for the condensation of amines with carboxylic acids, ${ }^{[2]}$ alternative methods have also been widely explored. ${ }^{[3]}$ Amongst these approaches, isocyanates have recently received attention as a reactive and mass-efficient synthon for the amide unit. Specifically, transition metal-catalyzed cross-coupling reactions of isocyanates have been developed, with both pre-formed organometallic species ${ }^{[4]}$ and following aryl $\mathrm{C}-\mathrm{H}$ activation ${ }^{[5]}$ (Figure 1a). These methods, however, generally require forcing conditions and excess reagents, and are only applicable to $\mathrm{sp}^{2}$-hybridized coupling partners, due to $\beta$-hydride elimination issues. ${ }^{[6]}$ A nickelcatalyzed reductive cross-electrophile coupling of isocyanates with alkyl bromides has recently been reported, ${ }^{[7]}$ alongside similar methods involving phenol and benzylic alcohol derivatives, ${ }^{[8]}$ aryl iodides, ${ }^{[9]}$ (Figure $1 \mathrm{~b}$ ), or the hydroamidation of alkynes. ${ }^{[10]}$ However, these approaches are generally limited to hindered isocyanates, and require stoichiometric quantities of a metal as the terminal reductant.

Non-catalyzed methods have capitalized on the prominent electrophilicity of the isocyanate moiety ${ }^{[11]}$ by reacting it directly with a more nucleophilic organometallic reagent (Figure 1c). This general approach has, however, received very little attention, considering its theoretical simplicity. Organozinc reagents have been shown to react ineffectively, in most cases providing the carbamate product rather than the amide. ${ }^{[12]}$ Likewise, organolithium and Grignard reagents have generally

[a] Prof. Dr W. J. Kerr, Dr D. M. Lindsay, Dr J. D. Williams Department of Pure and Applied Chemistry WestCHEM, University of Strathclyde

295 Cathedral Street, Glasgow, G1 1XL (UK)

E-mail: w.kerr@strath.ac.uk

[b] Dr S. G. Leach, Dr J. D. Williams

GlaxoSmithKline

Medicines Research Centre

Gunnels Wood Road, Stevenage, Hertfordshire, SG1 2NY (UK)

E-mail: stuart.g.leach@gsk.com

Supporting information for this article is given via a link at the end of the document. a) Transition metal-catalysed reactions with isocyanates

$$
\mathrm{R}^{1} \mathrm{NCO} \underset{\text { catalyst }}{\stackrel{\mathrm{R}^{2} \mathrm{~B}(\mathrm{OR})_{2} / \mathrm{R}^{2} \mathrm{H}}{\longrightarrow} \mathrm{R}^{1} \underset{\mathrm{N}}{\stackrel{\mathrm{H}}{\mathrm{O}}} \mathrm{R}^{2}} \begin{aligned}
& -\mathrm{R}^{2}=\mathrm{sp}^{2} \text { only } \\
& \text { - Excess reagents }
\end{aligned}
$$

b) Cross-electrophile couplings of isocyanates

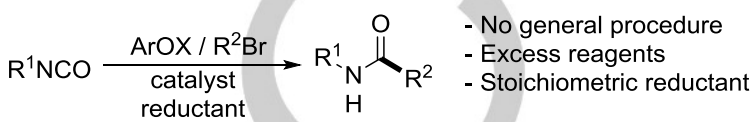

c) Stoichiometric organometallic reactions with isocyanates

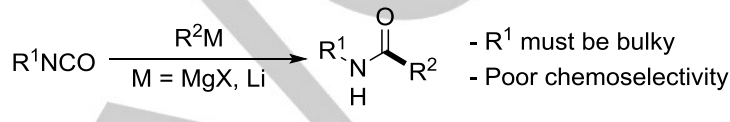

d) This work: direct reaction of Grignard reagents with isocyanates in flow

$$
\begin{aligned}
& \mathrm{R}^{2} \mathrm{MgX}-\boldsymbol{R}^{\mathbf{1}}=\text { Hindered or unhindered }
\end{aligned}
$$

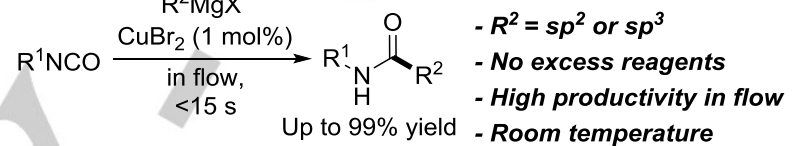

Figure 1. Synthesis of amides from isocyanates, by catalytic reactions, and direct reactions with stoichiometric organometallic reagents.

delivered poor product yields, or been effective only in specific cases, ${ }^{[13]}$ until the more recent report of a protocol for the reaction of isocyanates with Grignard reagents. ${ }^{[14]}$ Despite this notable advance, the latter method appears to be limited to sterically hindered isocyanates. To our knowledge, no method is currently capable of providing more widely effective amidation of both sterically hindered and unhindered isocyanates, using $\mathrm{sp}^{2}$ and $\mathrm{sp}^{3}$-coupling partners. Herein, we describe the development of the first protocol in which such a general approach is fulfilled, facilitated by the application of flow chemistry (Figure 1d).

Our initial studies were founded on an interest in industrially-relevant amidation methods. This led to a detailed exploration of the previously-reported ${ }^{[14]}$ reaction of Grignard reagents with isocyanates (Scheme 1). From these explorations it was observed that a successful reaction requires a sterically bulky isocyanate, otherwise formation of a deleterious acylurea

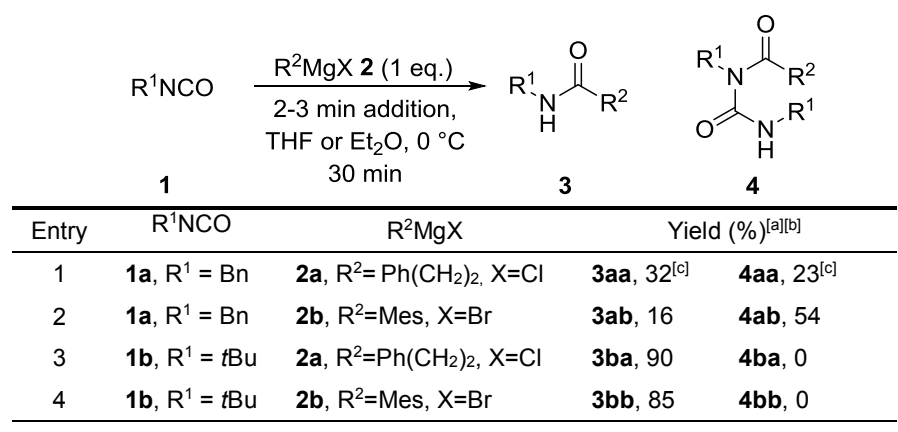

Scheme 1. Initial studies, demonstrating poor reaction performance with unhindered reaction partners. [a] Isolated yield of product shown. [b] Yield of $\mathbf{4}$ based on isocyanate starting material. [c] HPLC assay yield of product. 
by-product (4aa and $\mathbf{4 a b}$ ) was observed in significant quantities. ${ }^{[15]}$ Attempts to prevent the formation of acylurea through modulating temperature, addition regime, and reactant stoichiometry delivered no practicable improvement. ${ }^{[16]}$

We then focused on a more detailed study of the low yielding and inefficient coupling of unhindered reaction partners $1 \mathrm{a}$ and 2a. Surprisingly, the rate of Grignard reagent addition was found to have a significant impact upon reaction performance (Figure 2). Slower Grignard addition considerably reduced the yield of desired amide $3 \mathrm{aa}$; from $69 \%$ using a fast addition by syringe, to $51 \%$ when a 10 second addition period was employed, and appreciable lower yields of 3aa over longer Grignard addition times.

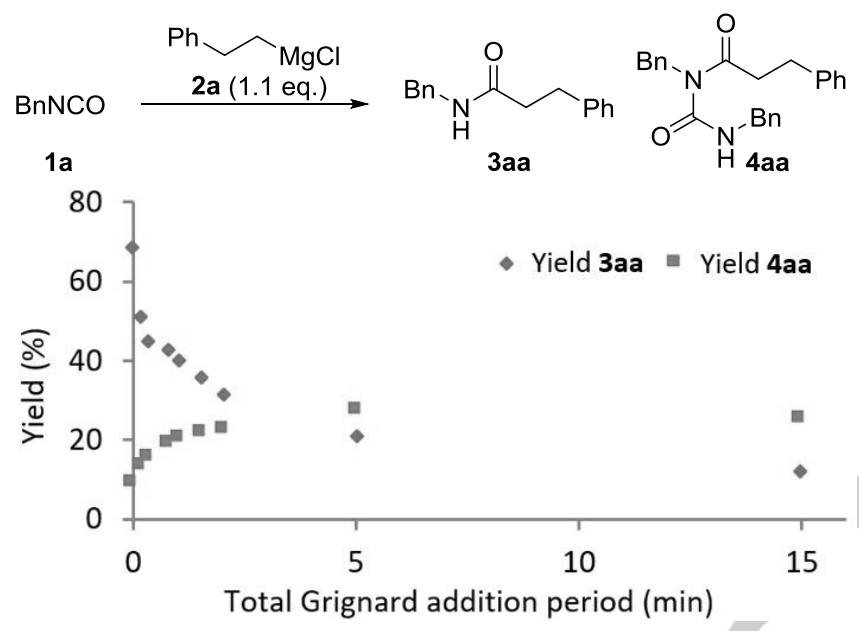

Figure 2. HPLC assay yields of desired amide 3aa and acylurea by-product 4aa versus total Grignard addition period. Reaction conditions: 1a (1 mmol), 2a $\left(1.1 \mathrm{mmol}, 0.85 \mathrm{M}\right.$ solution in THF), THF $(4 \mathrm{~mL}), 0{ }^{\circ} \mathrm{C}$, addition periods were applied using a syringe pump.

This apparent requirement for rapid reagent addition then guided us towards the application of continuous flow chemistry. ${ }^{[17]}$ Alongside addressing safety issues, this technology has been recognized, in many cases, to augment reaction chemoselectivity through enhanced mass and heat transfer. [18] Indeed, when we applied a simple flow chemistry setup, a distinct improvement was observed immediately, with an increased yield of desired amide 3 aa to $90 \%{ }^{[19]}$

Since no further improvement could be achieved by parameter optimization, additives were screened in order to suppress formation of acylurea 4aa in batch, and successful conditions were then examined in flow (Scheme 2). Trimethylsilyl chloride (entry 2) was found to be effective in decreasing acylurea 4aa formation, presumably by transient protection of the reactive metalated intermediate. Several known Grignard de-aggregating agents ${ }^{[20]}$ were also tested, such as $\mathrm{LiCl}$ (entry 3), which, surprisingly, disfavored amide formation. Copper salts were then applied to the reaction, with a successful outcome observed when stoichiometric copper (I) iodide was employed (entry 4). Further screening of copper sources ultimately revealed a substoichiometric loading of copper (II)

\begin{tabular}{|c|c|c|c|}
\hline Entry & Additive (equiv.) & Yield 3aa (\%) ${ }^{[a]}$ & Yield 4aa (\%) ${ }^{[a]}$ \\
\hline $1^{[b]}$ & None & 69 & + \\
\hline $2^{[b]}$ & TMSCI (0.5) & 74 & 3 \\
\hline $3^{[b]}$ & $\mathrm{LiCl}(1)$ & 24 & 32 \\
\hline $4^{[b]}$ & Cul (1) & 82 & 4 \\
\hline $5^{[b]}$ & $\mathrm{CuBr}_{2}(0.1)$ & 78 & 2 \\
\hline $6^{[c]}$ & None & 90 & 8 \\
\hline $7^{[c]}$ & TMSCI (0.5) & 94 & 2 \\
\hline $8^{[c]}$ & $\mathrm{CuBr}_{2}(0.1)$ & 95 & 2 \\
\hline $9^{[c]}$ & $\mathrm{CuBr}_{2}(0.01)$ & 98 & 1 \\
\hline $10^{[c]}$ & $\mathrm{CuBr}_{2}(0.005)$ & 92 & 2 \\
\hline
\end{tabular}

Scheme 2. Screening of additives in batch and flow, in order to suppress byproduct formation. [a] Yield determined by HPLC analysis, versus an internal standard. [b] Reaction performed in batch. Conditions: 1a (1 mmol), 2a (1.1 $\mathrm{mmol}, 0.85 \mathrm{M}$ in THF), additive, THF (4 mL), rt. [c] Reaction performed in flow. Conditions: 1a (0.5 M THF solution with additive), 2a (0.5 M THF solution), $5 \mathrm{~mL} / \mathrm{min}$ pump rate, $10.6 \mathrm{~s}$ residence time, quenched into dilute $\mathrm{NH}_{4} \mathrm{Cl}$ solution.

bromide to be preferable (entry 5). Examining the use of TMSCl and $\mathrm{CuBr}_{2}$ in flow (entries 7-10) demonstrated that both additives retained their effect, when compared with the additivefree reaction (entry 6). Pleasingly, $\mathrm{CuBr}_{2}$ was found to deliver further improvements upon lowering its loading to 0.01 eq. (entry 9), but upon further reduction to 0.005 eq. a drop in yield of 3aa was observed (entry 10). ${ }^{[1]}$ As illustrated in Scheme 3 , the optimal flow condition process (cf. entry 9) delivered a $96 \%$ isolated yield of the desired amide, 3aa.

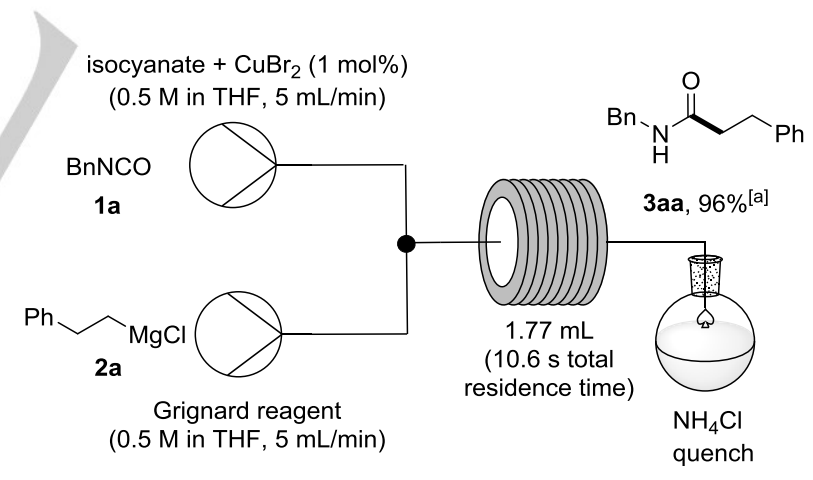

Scheme 3. Diagram of flow chemistry set-up for the optimised reaction of benzyl isocyanate 1a with phenethylmagnesium chloride $\mathbf{2 a}$. [a] Isolated yield of the desired amide 3 aa on a $2.5 \mathrm{mmol}$ scale.

With optimal conditions in hand, the substrate scope was examined with respect to the isocyanate component (Scheme 4). Gratifyingly, the developed protocol was found to give excellent results with the vast majority of isocyanates examined, including primary, secondary, and tertiary alkyl (3da, 3ea and 3ba), ${ }^{[22]}$ aryl (3ca), and substituted benzylic examples (3la and 3na; see also 3pa). This broad substrate scope demonstrates the applicability of this methodology to any level of steric bulk around the isocyanate. The reaction of most unhindered isocyanates were 


$\mathrm{R}^{1} \mathrm{NCO}+\mathrm{Ph}_{2 \mathrm{M}} \underset{\begin{array}{l}\mathrm{THF}, \mathrm{rt}, 10.6 \mathrm{~s} \\ \text { residence time }\end{array}}{\stackrel{\mathrm{CuBr}_{2}(1 \mathrm{~mol} \%)}{\longrightarrow}}$

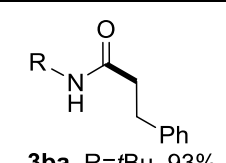

3ba, $R=t B u, 93 \%$

3ca, $\mathrm{R}=\mathrm{Ph}, 90 \%$

3da, $\mathrm{R}=n \mathrm{Bu}, 98 \%$

3ea, $\mathrm{R}=\mathrm{iPr}$, 98\%

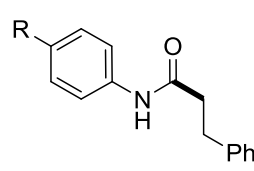

3fa, $\mathrm{R}=\mathrm{CO}_{2} \mathrm{Et}, 86 \%$

3ga, $\mathrm{R}=\mathrm{CN}, 68 \%$

3ha, $\mathrm{R}=\mathrm{Br}, 93 \%$

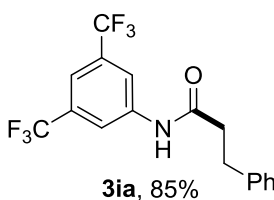

3ia, $85 \%$ 3ja, 95\%<smiles>NC(=O)CCc1ccccc1</smiles><smiles>CC(C)(C)OC(=O)N1CCC(NC(=O)CCc2ccccc2)CC1</smiles>
3oa, $89 \%$<smiles>C[C@H](NC(=O)CCc1ccccc1)c1ccccc1</smiles>

$3 \mathrm{ra}, 81 \%$<smiles>O=C(CCc1ccccc1)N[C@@H]1C[C@H]1c1ccccc1</smiles>

3pa, $91 \%$<smiles>O=C(CCc1ccccc1)Nc1ccc2c(c1)OCO2</smiles><smiles>CC(=O)c1ccc(NC(=O)CCc2ccccc2)cc1</smiles>

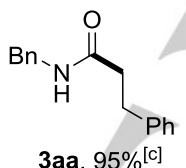

Scheme 4. Synthesis of secondary amides from a variety of isocyanates. Reaction conditions: isocyanate $11 \mathrm{mmol}, 0.5 \mathrm{M}$ in THF, with $\mathrm{CuBr}_{2}, 0.01$ $\mathrm{mmol}$ ), Grignard reagent $2 \mathrm{a}$ ( $1 \mathrm{mmol}, 0.5 \mathrm{M}$ in THF), $5 \mathrm{~mL} / \mathrm{min}$ pump rate, 10.6 $s$ residence time, quenched into dilute $\mathrm{NH}_{4} \mathrm{Cl}$ solution. Isolated yields are given [a] No erosion of stereochemical purity was observed. [b] Reaction performed at $0{ }^{\circ} \mathrm{C}$. [c] Reaction performed on a $6.6 \mathrm{~g}$ scale. $\mathrm{Cbz}=$ carbobenzyloxy

previously unreported, whilst a bulky substrate (leading to $3 \mathbf{b a}$ ) performed comparably with the previously described method. ${ }^{[14]}$ Additionally, an ester group was tolerated (3fa) without any requirement to lower the reaction temperature; moreover, incorporation of an aryl nitrile unit was shown to be possible (3ga). The successful reaction of a particularly electron-deficient aryl isocyanate (3ia) was also considered noteworthy, as this amide product would be challenging to prepare using standard amide coupling procedures. Electronic variation on aryl rings was well tolerated in general, with similar yields achieved for unsubstituted (3ca), electron-rich (3sa), and electron-poor (3ka) aryl isocyanates. Furthermore, the successful inclusion of a chloride or bromide substituent (3ma and 3ha) provides a handle for further functionalization in the product. Additionally, the developed method was also applicable to other alkyl isocyanates, providing good yields of products $\mathbf{3 j a}$, 3oa, 3qa, and 3ra, with maintenance of stereochemical integrity in the latter example. Even with an electrophilic and readily enolizable

ketone-containing isocyanate, amide 3 ta was isolated in moderate yield by reducing the reaction temperature to $0{ }^{\circ} \mathrm{C}$. Amide 3aa was also prepared on a $6.6 \mathrm{~g}$ scale in just twelve minutes of continuous reaction, maintaining an excellent $95 \%$ yield, and clearly demonstrating the inherent scalability of this flow procedure.

The substrate scope was then explored with respect to the Grignard reagent (Scheme 5). Simple aryl (3ab and 3ak), benzyl (3ac), and vinyl (3ad) reagents performed very well, with either the magnesium chloride or bromide Grignard reagent. Additionally, a range of functional units and steric variation within the Grignard reagent was tolerated successfully. For example, an aryl chloride remained intact (3af), as did a THP-protected phenol substrate (3ag). A bis(trimethylsilyl)-protected anilinic Grignard reagent was also reacted successfully, and its protecting groups removed in an acidic quench, to furnish the primary aniline (3al) in excellent yield. Furthermore, a heteroaryl Grignard reagent provided the thienyl amide (3ah) in good yield, and the hindered 2,4,6-tri-iso-propyl derivative (3am) was also prepared in a facile manner using this methodology. isoPropylmagnesium chloride and cyclopropylmagnesium bromide gave good yields of amides $\mathbf{3 a j}$ and $3 \mathbf{a e}$, respectively, but further

$$
\text { (1) }
$$

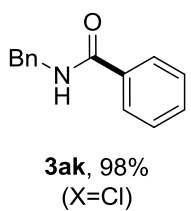

Scheme 5. Synthesis of secondary amides from a variety of Grignard reagents. Reaction conditions: isocyanate $1 \mathrm{a}(1 \mathrm{mmol}, 0.5 \mathrm{M}$ in THF, with $\left.\mathrm{CuBr}_{2}, 0.01 \mathrm{mmol}\right)$, Grignard reagent $2(1 \mathrm{mmol}, 0.5 \mathrm{M}$ in THF), $5 \mathrm{~mL} / \mathrm{min}$ pump rate, $10.6 \mathrm{~s}$ residence time, quenched into dilute $\mathrm{NH}_{4} \mathrm{Cl}$ solution. Isolated yields are given. [a] Reaction performed at $0.25 \mathrm{M}$ input solution concentrations. [b] $22 \%$ of regioisomeric by-product also isolated. [c] Product synthesized using $\operatorname{ArN}(\mathrm{TMS})_{2}$ protected Grignard reagent, and deprotected in quench using dilute $\mathrm{HCl}$. THP = tetrahydropyranyl; and TMS = trimethylsilyl. 
steric hindrance in an $\mathrm{sp}^{3}$ Grignard reagent was not tolerated, as evidenced by the tert-butyl Grignard failing to furnish the desired amide in an isolable quantity. ${ }^{[23]}$

In summary, a detailed assessment of the reaction of isocyanates with Grignard reagents has led to the development of a method in which, for the first time, a wide range of Grignard reagents and isocyanates can be coupled effectively, using a single, unified method. The use of flow chemistry imparts fast mixing of both reagents, which is critical to the success of this approach, but also confers upon this process an excellent scalability and safety profile. Furthermore, this protocol avoids the use of (stoichiometric) activating agents and provides an efficient and productive transformation, demonstrating that isocyanates are a valid surrogate synthon for the formation of amide bonds, particularly when a non-nucleophilic amine fragment is required. We anticipate that this development will facilitate the practicable employment of isocyanates as part of a genuine alternative synthetic strategy towards amide bondforming reactions.

\section{Acknowledgements}

The authors would like to thank the GlaxoSmithKline for financial support to J.D.W. We would also like to thank Miss Sarah Hunter, Mr. Andrew Payne, and Mr. Thomas Atherton for support with engineering developments, reaction calorimetry, and HRMS analysis, respectively.

Keywords: amides $\cdot \mathrm{C}-\mathrm{C}$ coupling $\cdot$ synthetic methods $•$ Grignard reaction $\bullet$ flow chemistry

[1] For reviews on amide bond forming reactions, see: a) S. D. Roughley, A. M. Jordan, J. Med. Chem. 2011, 54, 3451-3479; b) D. J. C Constable, P. J. Dunn, J. D. Hayler, G. R. Humphrey, J. L. Leazer, Jr. R. J. Linderman, K. Lorenz, J. Manley, B. A. Pearlman, A. Wells, A Zaks, T. Y. Zhang, Green Chem. 2007, 9, 411-420; c) A. K. Ghose, V. N. Viswanadhan, J. J. Wendoloski, J. Comb. Chem. 1999, 1, 55-68; d) J. S. Carey, D. Laffan, C. Thomson, M. T. Williams, Org. Biomol. Chem. 2006, 4, 2337-2347.

[2] For selected examples of catalytic condensations of amines with carboxylic acids, see: a) R. M. Al-Zoubi, O. Marion, D. G. Hall, Angew. Chem. Int. Ed. 2008, 47, 2876-2879; Angew. Chem. 2008, 120, 29182921; b) S. Fatemi, N. Gernigon, D. G. Hall, Green Chem. 2015, 17, 4016-4028; c) E. K. W. Tam, Rita, L. Y. Liu, A. Chen, Eur. J. Org. Chem. 2015, 1100-1107; d) H. Noda, M. Furutachi, Y. Asada, M. Shibasaki, N. Kumagai, Nat. Chem. 2017, 9, 571-577; e) C. L. Allen, A. R. Chhatwal, J. M. J. Williams, Chem. Commun. 2012, 48, 666-668.

[3] For an in-depth review, see: R. M. de Figueiredo, J.-S. Suppo, J.-M. Campagne, Chem. Rev. 2016, 116, 12029-12122.

[4] a) T. T. S. Lew, D. S. W. Lim, Y. Zhang, Green Chem. 2015, 17, 51405143; b) T. Miura, Y. Takahashi, M. Murakami, Chem. Commun. 2007 3577-3579; c) E. Kianmehr, A. Rajabi, M. Ghanbari, Tetrahedron Lett. 2009, 50, 1687-1688; d) T. Koike, M. Takahashi, N. Arai, A. Mori, Chem. Lett. 2004, 33, 1364-1365.

[5] a) K. Muralirajan, K. Parthasarathy, C.-H. Cheng, Org. Lett. 2012, 14 4262-4265; b) W. Liu, J. Bang, Y. Zhang, L. Ackermann, Angew. Chem. Int. Ed. 2015, 54, 14137-14140; Angew. Chem. 2015, 127, 1434314346; c) J. Li, L. Ackermann, Angew. Chem. Int. Ed. 2015, 54, 85518554; Angew. Chem. 2015, 127, 8671-8674; d) X.-Y. Shi, A. Renzetti S. Kundu, C.-J. Li, Adv. Synth. Catal. 2014, 356, 723-728; e) K. D
Hesp, R. G. Bergman, J. A. Ellman, J. Am. Chem. Soc. 2011, 133 11430-11433; f) X. Geng, C. Wang, Org. Biomol. Chem. 2015, 13, 7619-7623.

[6] For an overview of the problems associated with $\beta$-hydride elimination, see: T.-Y. Luh, M.-K. Leung, K.-T. Wong, Chem. Rev. 2000, 100 3187-3204

[7] E. Serrano, R. Martin, Angew. Chem. Int. Ed. 2016, 55, 11207-11211; Angew. Chem. 2016, 128, 11373-11377.

[8] A. Correa, R. Martin, J. Am. Chem. Soc. 2014, 136, 7253-7256.

[9] J.-C. Hsieh, C.-H. Cheng, Chem. Commun. 2005, 4554-4556.

[10] X. Wang, M. Nakajima, E. Serrano, R. Martin, J. Am. Chem. Soc. 2016 , 138, 15531-15534.

[11] See also, amidations of isocyanates with carboxylic acids and thioacids: a) K. Sasaki, D. Crich, Org. Lett. 2011, 13, 2256-2259; b) D. Crich, K. Sasaki, Org. Lett. 2009, 11, 3514-3517.

[12] H. Yang, D. Huang, K.-H. Wang, C. Xu, T. Niu, Y. Hu, Tetrahedron 2013, 69, 2588-2593.

[13] For selected examples of direct reactions of stoichiometric organometallics with isocyanates, see: a) V. Pace, L. Castoldi, W. Holzer, Chem. Commun. 2013, 49, 8383-8385; b) D. Seyferth, R. C Hui, Tetrahedron Lett. 1984, 25, 5251-5254; c) K. A. Parker, E. G. Gibbons, Tetrahedron Lett. 1975, 16, 981-984; d) E. Chorell, P. Das, F. Almqvist, J. Org. Chem. 2007, 72, 4917-4924; e) A. V Lygin, A. de Meijere, Org. Lett. 2009, 11, 389-392.

[14] a) G. Schäfer, C. Matthey, J. W. Bode, Angew. Chem. Int. Ed. 2012, 51 , 9173-9175; Angew. Chem. 2012, 124, 9307-9310; See also, an extension of this methodology to masked isocyanates: b) G. Schäfer, J W. Bode, Org. Lett. 2014, 16, 1526-1529.

[15] Formation of an analogous product was also observed in the ironcatalyzed hydrophosphination of isocyanates: H. R. Sharpe, A. M. Geer, W. Lewis, A. J. Blake, D. L. Kays, Angew. Chem. Int. Ed. 2017, 56 4845-4848; Angew. Chem. 2017, 129, 4923-4926.

[16] For details, see section 3.1 in the supporting information.

[17] For selected applications of Grignard and other main group organometallic reagents in flow, see: a) L. Huck, A. de la Hoz, A. Diaz Ortiz, J. Alcázar, Org. Lett. 2017, 19, 3747-3750; b) M. E. Kopach, K. P. Cole, P. M. Pollock, M. D. Johnson, T. M. Braden, L. P. Webster, J. McClary Groh, A. D. McFarland, J. P. Schafer, J. J. Adler, M Rosemeyer, Org. Process Res. Dev. 2016, 20, 1581-1592; c) E. Riva, S. Gagliardi, M. Martinelli, D. Passarella, D. Vigo, A. Rencurosi, Tetrahedron 2010, 66, 3242-3247; d) T. Brodmann, P. Koos, A. Metzger, P. Knochel, S. V. Ley, Org. Process Res. Dev. 2012, 16, 1102-1113; (e) H. Wakami, J.-I. Yoshida, Org. Proc. Res. Dev. 2005, 9, 787-791; (f) D. L. Browne, M. Baumann, B. H. Harji, I. R. Baxendale, S. V. Ley, Org. Lett. 2011, 13, 3312-3315; (g) P. R. D. Murray, D. L. Browne, J. C. Pastre, C. Butters, D. Guthrie, S. V. Ley, Org. Process Res. Dev. 2013, 17, 1192-1208; (h) J. A. Newby, D. W. Blaylock, P. M. Witt, J. C. Pastre, M. J. Zacharova, S. V. Ley, D. M. Browne, Org Process Res. Dev. 2014, 18, 1211-1220; (i) M. R. Becker, M. A Ganiek, P. Knochel, Chem. Sci. 2015, 6, 6649-6653; (j) M. Ketels, M. A Ganiek, N. Weidmann, P. Knochel. Angew. Chem. Int. Ed. 2017, 56, 12770-12773; Angew. Chem. 2017, 129, 12944-12948.

[18] For reviews of organometallic reactions in flow, see: a) B. Gutmann, D. Cantillo, C. O. Kappe, Angew. Chem. Int. Ed. 2015, 54, 6688-6728 Angew. Chem. 2015, 127, 6788-6832; b) M. Movsisyan, E. I. P. Delbeke, J. K. E. T. Berton, C. Battilocchio, S. V. Ley, C. V. Stevens Chem. Soc. Rev. 2016, 45, 4892-4928; c) M. B. Plutschack, B. Pieber, K. Gilmore, P. H. Seeberger, Chem. Rev. 2017, 117, 11796-11893; (e) J.-I. Yoshida, A. Nagaki, T. Yamada, Chem. Eur. J. 2008, 14, 74507459; (f) J.-I. Yoshida, Y. Takahashi, A. Nagaki, Chem. Commun. 2013 49, 9896-9904.

[19] See section 2.3 in the supporting information for details.

[20] R. L.-Y. Bao, R. Zhao, L. Shi, Chem. Commun. 2015, 51, 6884-6900; see also the additional detail within the supporting information.

[21] Investigation into the additive's mechanism of action is currently underway. 
[22] It has been shown that the tert-butyl group of amide 3 ba can be removed under Lewis acidic conditions, giving facile access to the corresponding primary amide; see, A. K. Mahalingam, X. Wu, M. Alterman, Tetrahedron Lett. 2006, 47, 3051-3053.

[23] The corresponding acylurea product (4an), equivalent to $4 \mathrm{aa} / \mathbf{4 a b}$, was isolated in $44 \%$ yield; see supporting information for further details. 
Entry for the Table of Contents (Please choose one layout)

Layout 2:

\section{COMMUNICATION}

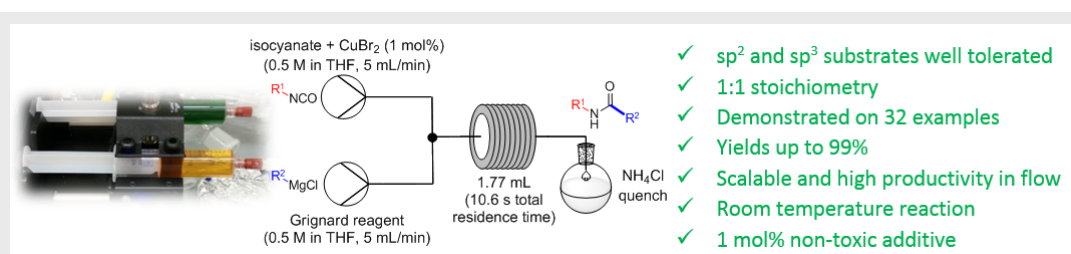

Isocyanates represent a reactive and mass-efficient synthon for amide bondformation, yet their use with stoichiometric organometallic reagents has, in the past, been hindered due to by-product formation in the majority of examples. We report the development of a straightforward and widely applicable protocol, enabled by continuous flow. For the first time, $\mathrm{sp}^{2}-$ and $\mathrm{sp}^{3}$-carbon fragments can be successfully reacted with a wide range of isocyanates using a single method.
Jason D. Williams, William J. Kerr, ${ }^{*}$

Stuart G. Leach, * and David M. Lindsay

Page No. - Page No.

\section{A Practical and General Amidation} Method from Isocyanates Enabled by Flow Technology 